\title{
Nietzsche y la escritura
}

\author{
JOSÉ LUIS PUERTAS
}

\section{El JUEGO LITERARIO Y LA FRAGMENTARIEDAD}

Entre el instante en que Nietzsche recibe en Basilea el primer ejemplar de El nacimiento de la tragedia y en el que se apresta en Turín a corregir las pruebas de los Ditirambos de Dioniso, apenas han transcurrido dieciocho años. En este corto espacio de tiempo el filólogo Friedrich Nietzsche ha podido desentrañar la falsedad de 'nuestra' cultura actual, redescubrir el sentido original de lo dionisíaco, denunciar la amputación instintiva de la racionalidad, revelar los mecanismos lingüísticos de la consciencia y el pensamiento, bucear en los orígenes de la moral, perderse en la anulación del tiempo del eterno retorno, anunciar contra 'nuestra' decadencia la aniquilación de todo lo parasitario...

La obra de Nietzsche es, pues, de una vastedad y diversidad sorprendentes. No sólo dejó publicada una docena de libros de estilos contrastados, sino que también ha legado una enorme cantidad de anotaciones en cuadernos y folios sueltos, a la que hay que añadir un ingente intercambio epistolar. Gracias a ello, Curt Paul Janz ha podido reconstruir, a veces casi en forma de dietario, el transcurso de la obra y la vida de Nietzsche1.

1 En su monumental biografía Friedrich Nietzsche, Carl Hanser Verlag, München, 1978 (traducción al castellano de Jacobo Muñoz e Isidoro Reguera, Friedrich Nietzsche, Alianza Editorial, Madrid, 1985). 
Conocemos asítodos sus movimientos, sus lecturas, sus pequeñas y grandes alegrías y desilusiones, sus gustos musicales y teatrales, sus jaquecas, sus comidas... conocemos prácticamente todo aquello que dejase consignado por escrito. La escritura parece así erigirse en el punto central de la existencia de Nietzsche. Giorgio Colli ha subrayado esta dimensión 'literaria' —o mejor, 'literata'— de la persona Nietzsche. El gran desacralizador habría sido finalmente, sin embargo, incapaz de desacralizar la escritura. La extensión del corpus nietzscheano refleja por ello un desequilibrio de fondo entre tema e instrumento expresivo $^{2}$. La lectura de los fragmentos póstumos ahonda aún más esta impresión de desajuste señalada por Colli. A lo largo de centenares de páginas aparecen y se repiten de manera compulsiva los mismos temas. Ciertamente, el acto mismo de escritura se revela el núcleo de la obra de Nietzsche; pero al mismo tiempo anida en ella la aspiración de superar la limitación de la letra escrita. Se tiene entonces la sensación de asistir a una especie de juego de transparencia. La vivencia se vierte en la escritura en un anhelo de comunicación que se sabe imposible.

La posición de Nietzsche ante la escritura está marcada por la ambigüedad. Por un lado se despliega en la forma de un incesante monólogo; por el otro, se denuncia su insuficiencia. El último parágrafo de Más allá del bien y del mal pone de manifiesto la penuria de la escritura. Con ella, nos dice aquí Nietzsche, eternizamos lo que ya no puede vivir ni volar. Las palabras escritas pintan los pensamientos con los colores de la tarde, pero son incapaces de reproducir sus fulgores cuando nacen por la mañana 3 . La prevención contra el oficio literario, o contra el vicio de la lectura, surge reiteradamente en los más variados pasajes. Como filólogo, Nietzsche nos advierte de la contranaturaleza de la lectura silenciosa ${ }^{4}$. Censura la perversión del erudito, un decadente incapaz de pensar si no hojea unos centenares de páginas, que dilapida su fuerza vital en sumergirse en los pensamientos de

2 Cf. G. Colli, Después de Nietzsche, tr. Carmen Artal, Ed. Anagrama, Barcelona, 1978, capítulo «La literatura como vicio», § Impaciencia de la vendimia, pp. 99-100.

3 KGW VI 2, p. 249.

4 En La exposición de la retórica antigua, KGW II 4, p. 425, dentro de la discusión sobre la naturalidad del lenguaje, se subraya la pérdida de la oralidad del libro en relación a la Antigüedad. Una brevísima anotación entre abril y junio de 1885 comenta a este respecto que «los antiguos leían en voz alta.» KGW VIII 3, 34\{15], p. 147. 
otro. «A primera hora de la mañana cuando amanece el día, en el frescor, en la aurora de su fuerza, leer un libro - iesto es lo que yo llamo vicioso!»5. Reniega igualmente del oficio de escritor. Confiesa una náusea - verdadera o fingida - por el papel impreso y propugna un, para él imposible, comedimiento en la escritura 6 . Los términos 'literatura' y 'literato' adquieren así para Nietzsche un marcado sentido peyorativo ${ }^{7}$. Al inicio del prólogo de 1886 a la segunda parte de Humano, demasiado bumano hace la siguiente confesión sobre sus escritos: «Sólo se debe hablar donde no es lícito callarse, y sólo de aquello que se ha superado —-Todo lo demás son habladurías, 'literatura', falta de disciplina. Mis escritos sólo hablan de mis superaciones»8. De estas fechas data también una muy interesante carta sobre este mismo tema que Nietzsche enviara a su amigo y antiguo colega en Basilea Franz Overbeck. El punto de vista adoptado en ella es justamente el opuesto al del prólogo anteriormente mencionado. La obra no aparece ahora como una superación de la literatura, sino que, por el contrario, ella misma se ve reducida a mera letra escrita, como si se tratara de una especie de último recurso que de todas maneras resultase insuficiente. En lugar de depositar lo mejor de sí mismo en almas selectas - confiesa con amargura Nietzsche-, se ha visto obligado «con sus ojos mediociegos y dolientes, a 'hacer literatura' — itodo ello es tan demente! ¡tan duro!»9

A pesar de lamentaciones como ésta sobre la insuficiencia de 'hacer literatura', en sus cuadernos de notas Nietzsche se abandonó a toda suerte de ensoñaciones sobre libros futuros. Ya durante sus años de profesor en Basilea, proyecta la serie de las Consideraciones intempestivas - trece en total—, pero también calcula el tiempo que tardará en realizarlas, así como la edad que tendrá cuando las haya acabado ${ }^{10}$.

5 KGW VI 3, p. 291.

6 Cf. la carta a Malwida von Meysenbug del 6 de abril de 1873, KGB II 3, p. 142.

7 Cf., por ej., la carta a Carl von Gersdorff del 21 de julio de 1875, KGB II 5, p. 87 o la dirigida a Köselitz (Peter Gast) el 6 de abril de 1883, KGB III 1, p. 359.

8 KGW IV 3, p. 3.

9 KGB III 3, p. 136.

10 Para la serie completa de Intempestivas, véase la anotación de otoño de $1873 \mathrm{KGW}$ III 4, 30[38], pp. 334-335. Para los cálculos de tiempo que conllevaría tal empresa y la edad que tendría al finalizar ( 45 o 46 años), cf. las anotaciones de la primavera-verano $1875 \mathrm{KGW}$ $5[42]$, p. 128 y 5[161], p. 161. 
Posteriormente, esboza recopilaciones de sus obras publicadas ${ }^{11}$. Planea los libros más diversos — de algunos de ellos sólo disponemos del título acompañado, a lo sumo, de una sucesión de capítulos ${ }^{12}$. En otras ocasiones, llega a fantasear con la recepción de sus escritos. Poco antes de la publicación de El nacimiento de la tragedia anuncia una porción de inmortalidad para el autor de la viñeta (un grabado de Prometeo) que ilustrará la cubierta del libro' 13 . En los años posteriores a AsíbablóZ arathustra, imagina cómo y cuándo se descubrirá su obra, el mayor acontecimiento en los últimos dos mil años de historia. Respecto a esta cuestión, considera lo más conveniente que tal cosa no sucediera hasta ya entrado el siglo $\mathrm{XX}^{14}$.

En los últimos años de vida consciente de Nietzsche la preocupación por la recepción de su obra adquiere una importancia vital. Entra en litigio con su antiguo editor, Schmeitzner, al objeto de recuperar los derechos de sus primeros libros - y evitar con ello cualquier asociación indeseable con el movimiento antisemita. Al mismo tiempo, se esfuerza por mostrar la profunda unidad que alienta sus escritos. A tal objeto escribe, en 1886, una serie de prólogos para sus anteriores publicaciones. Sus últimos libros incluyen una breve exposición - polémica- de su pensamiento, Crepuísculo de los ídolos, y una biografía y presentación del conjunto de su obra, Ecce homo. La intención de estos escritos es la de eliminar cualquier equívoco sobre su persona o sus libros. "; Escuchadme! Pues yo soy tal y tal. ;Sobre todo no me confundáis.» 15

Dentro de esta preocupación por la recepción de la obra hay que incluir también una curiosa táctica de 'adiestramiento' o 'selección'

11 Por ej. Nietzsche proyecta en julio-agosto de 1882 con el curioso título Vademecum, Vadetecum, una edición conjunta de Humano, demasiado humano, Aurora y La gaya ciencia, cf. KGW VII 1, 1[13], p. 7.

12 Es el caso, por ej., de una obra teórica sobre la moral, que llevaría el sugerente título de Die Unschuld des Werdens [La inocencia del devenir], y que Nietzsche anunciara a Köselitz en carta del 3 de septiembre de 1883 (KGB III 1, p. 445). Una anotación de ese mismo verano, KGW VII 1, 8[26], p. 353 especifica el contenido de la obra, así como su división en capítulos. Sin embargo, al leer los apuntes de este periodo, no se encuentra ningún desarrollo concreto de estos capítulos, sino la recopilación habitual de anotaciones diversas, junto a esbozos de Zarathustra.

13 Cf. la carta a Gersdorff del 18 de noviembre de 1871, KGB II 1, p. 243.

14 Cf. la carta a Meysenbug del 12 de mayo de 1887, KGB III 5, p. 70.

15 KGB VI 3, p. 255. 
del lector, a la que Nietzsche hace continua referencia en sus últimos escritos con la utilización marcada de los términos Zucht, Züchtung y Züchten, o en la continuidad y contraposición de Selbstsucht (egoísmo) y Selbstzucht (autodisciplina). Básicamente, dicha táctica pretende crear paulatinamente al lector de la obra. Puesto que su pensamiento encierra un tipo de vivencia sin precedentes, la comunicación será imposible hasta que no se haya producido una transformación de la sensibilidad. Ésta es la razón — se afirma en Ecce bomo- por la que no se ha comprendido un libro como $A$ sí habló Zarathustra. faltaba el lector capaz de hacerlo y éste sólo surgirá, precisamente, a consecuencia de su lectura ${ }^{16}$. Este nuevo juego literario, con el que Nietzsche pretende asegurar la comunicación mediante una 'selección' del lector, queda al descubierto en una carta dirigida a Overbeck, el 12 de octubre de 1886, inmediatamente posterior a la publicación de Más allá del bien y del mal. En ella reconoce que le ha tranquilizado que «un lector tan sutil y benévolo» como el mismo Overbeck no haya sin embargo adivinado lo que él realmente quiere. Antes de ser comprendido debe suministrar primero una serie de premisas educativas, al objeto de adiestrar a sus propios lectores, a aquellos que les es lícito considerar sus problemas ${ }^{17}$.

Este pasaje de la correspondencia ilustra una actitud característica del último Nietzsche respecto a su propia actividad 'literaria'. La necesidad de preparar a los lectores conlleva un juego de ocultación en la escritura: el mensaje no debe revelarse directamente: su exposición se posterga hacia el futuro. En Más allá del bien y del mal el mismo Nietzsche se encarga de llamar la atención sobre el ejercicio de simulación que supone en el fondo su escritura. En este sentido advierte de la necesidad de la máscara para todo espíritu profundo, lo que conlleva fácilmente a un error en la interpretación de cada una de sus palabras y signos vitales 18 . Él mismo confiesa haber hecho «todo lo posible para ser comprendido con dificultad», motivo por el cual su lector habrá de poseer cierta sutileza en la interpretación 19 . Tal esconderse en la escritura sería también una exigencia de su propio

\footnotetext{
16 Ibid., p. 297.

17 KGW III 3, p. 264.

18 KGW VI 2, p. 54.

19 Ibid., p. 41.
} 
pensamiento, porque, como dice en otro aforismo de este mismo libro, «uno ya no ama suficientemente su conocimiento, desde el momento en que lo comunica» 20 .

Tal lógica literaria de la obra - reconocimiento de la insuficiencia de la escritura, selección de lector, juego de ocultación— no viene sino a subrayar el carácter fragmentario del pensamiento de Nietzsche. Si bien es cierto que en su última etapa, la filosofía nietzscheana deriva hacia formulaciones dogmáticas, sigue existiendo a pesar de ello un trasfondo asistemático que, más que las dificultades prácticas a las que tuvo que enfrentarse Nietzsche, acabaría frustrando los continuos proyectos de redacción de una obra capital.

Según esta perspectiva, el pensamiento de Nietzsche iría unido a su formulación fragmentaria, como reflejo de esa tensión del lenguaje que estalla en el aforismo ${ }^{21}$. El intento de una exposición sistemática ya sería por ello el resultado de una falsificación de dicha discontinuidad. Nietzsche, a pesar de sus proyectos literarios, ha puesto de relieve esta característica de su escritura - y su pensamiento—en los más variados pasajes. En Humano, demasiado bumano recalca la necesidad del espíritu, si quiere continuar siéndolo, de cambiar de opinión, de manera semejante a como la serpiente cambia de piel22. En otro pará-

20 Ibid., p. 100. Respecto a esta cuestión, en una anotación póstuma de abril-junio de 1885, KGW VII 3, 34[147\}, pp. 189-190, Nietzsche comenta lo siguiente: «He pensado tantas cosas prohibidas [... ] así contemplo siempre con admiración que aún pueda comunicar algo. Como si supiera que mis líneas de pensamiento fuesen mejores que los pensamientos comunicados. / A cuántos eruditos puedo ocupar, y quizás ya lo haya hecho en casos particulares—».

21 Ha sido la corriente de interpretación francesa de la obra de Nietzsche en los años 60 y 70, con autores interesados sobre todo por la problemática literaria, como Maurice Blanchot (L'Entretien infinz) o Pierre Klossowski, la que ha puesto de relieve la concatenación entre contenido y expresión en la filosofía nietzscheana. Así sobre la fragmentariedad de la escritura de Nietzsche, Klossowski — en el capítulo «Note additionnelle à la sémiotique de Nietzsche» en Nietzsche et le cercle vicieux, París, 1969, p. 359- destaca que «el aforismo de Nietzsche tiende por consecuencia a devolver al acto mismo de pensar su virtud de resistencia a toda 'conceptualización'». En esta misma línea de interpretación Michel Haar —en Par-délà le nibilisme, PUF, París, 1998, pp. 192-193 - concibe el aforismo en la escritura nietzscheana como una 'intensidad del estilo'. Remitiendo a la etimología del término (apo-horismos), habla de una irrupción de perspectivas imposible de retener en un «horizonte único, absoluto, dominante». En consecuencia, según Haar, «el aforismo [de Nietzsche] hace estallar o más bien desmenuza la lógica del ser».

22 KGW V 1, p. 334. 
grafo de este mismo libro señala que los pensamientos inacabados, propios del poeta, pueden tener más valor que el pensar sistemático del filósofo, —debido precisamente a esa inseguridad de su horizonte que le hace permanecer abierto como camino para otros pensamientos 23 . Más tarde, en una anotación escrita entre mayo y julio de 1885 , Nietzsche concibe «los libros más profundos e inagotables» a partir del «carácter repentino y aforístico de los Pensamientos de Pascal»24. A esta defensa de la fragmentariedad, del valor de lo incompleto, cabría añadir la advertencia contra la falta de honestidad del pensamiento sistemático, repetida en dos momentos distintos de la obra publicada: en el aforismo 318 de Aurora — con el título significativo de « $i C u i-$ dado con los sistemáticos!» 25 _ y en el 26 de los «Dichos y flechas» en Crepuísculo de los ídolos 26.

La filosofía de Nietzsche, como estamos viendo en esta revisión de sus propios comentarios, no puede separarse de su misma materialidad como escritura. La aspiración a inculcarse en almas elegidas —en una especie de renacimiento de la mayéutica socrática- se ve contrarrestada por la realidad literaria de la obra. Los libros publicados por Nietzsche, sobre todo los de sus dos últimos años de vida consciente, reflejan la tensión entre esos dos extremos: por un lado el anhelo de comunicación, con la elaboración de un ideal del 'nosotros'; por el otro, el reconocimiento de su imposibilidad y la consiguiente aceptación de la soledad. En el siguiente apartado intentaremos seguir este desarrollo de la escritura de Nietzsche. En contraposición al magma de los fragmentos póstumos — reflejo de aquella discontinuidad del pensamiento que estalla en el aforismo-, la obra publicada plantea una utópica búsqueda del 'nosotros': utópica, porque en ella se plantea tanto un rechazo radical del orden establecido como una pretensión de transformación del conjunto de la realidad 27 .

23 Ibid., pp. 172-173.

24 KGW VIII 3, 35[31], p. 244.

$25 \mathrm{KGW}$ V 2, p. 230.

$26 \mathrm{KGW}$ VI 3, p. 57. Es interesante indicar que Nietzsche rehace en varias ocasiones este aforismo en sus cuadernos de notas: cf. KGW VIII 2, 9[181], 9[188], 11[410] y KGW VIII 3, 18[4].

27 Para una interpretación global del utopismo europeo nos remitimos a la obra de Antonio Monclús, Elpensamiento utópico contemporáneo, CEAC, Madrid, 1981. 


\section{LA INVENCIÓN DEL 'NOSOTROS’}

Cada uno de los libros de Nietzsche se proyecta en una especie de anhelo de transfiguración. La posición crítica se radicaliza hasta convertirse en un rechazo frontal. Tal posición beligerante —o polémica—se manifiesta en todos sus escritos. Es lo que él denomina el lado destructor de su tarea constructiva: la desvalorización que precede la transvaloración, por utilizar la expresión de su pensamiento de madurez.

En El nacimiento de la tragedia la propuesta de transfiguración se cifra en el resurgir del mito por medio del vehículo de la música wagneriana. Al mismo tiempo se reconoce al enemigo en la cultura de la actualidad (Jetztzeit) 28 , en el teatro de la masa - el público-y su representante, el periodista. En la serie de las Consideraciones intempestivas, al ideal de reconstrucción de la cultura en una unidad estética —singularizada en los modelos de Wagner y Schopenhauer- se contrapone la autocomplacencia del filisteísmo de un David Strauss o la hipertrofia, enemiga de la vida, del historicismo. La función disgregadora del erudito (Gelebrter) se revela así el principal obstáculo de la actividad unificadora del genio, en tanto que manifestación de la unidad artística de un pueblo. Incluso el modelo griego, como ideal de cultura, actúa primero en Nietzsche mediante un efecto de rechazo. Lo griego es así lo otro: lo que produce la dislocación del presente.

En Humano, demasiado bumano, a pesar del aparente cambio de perspectiva de la filosofía de Nietzsche, su pensamiento polémico sigue moviéndose dentro de las coordenadas de la crítica de la cultura fijadas en El nacimiento de la tragedia. En este sentido, el genio adopta en este libro la forma del 'espíritu libre'29. Su misión es la de frenar la 'barbarie' del presente ante la perspectiva de una «degeneración total de la cultura mundial»30. El tono de crítica se acentúa a partir de Más allá del bien y del mal. Desde ese momento Nietzsche escribe siempre contra algo, cuando no contra alguien. El éxito póstumo de Crepúsculo

28 Para la crítica de 'la cultura alemana de la actualidad' (die deutsche Kultur der Jetztzeit), cf. el cuarto de los Cinco prólogos a cinco libros no escritos, «La relación de la filosofía schopenhaueriana con una cultura alemana», KGW III 2, p. 274.

29 Cf. los aforismos 230 «Espíritu fuerte» y 231 «El surgimiento del genio» de $H u$ mano, demasiado bumano I, KGW IV 2, pp. 197-198.

30 Ibid., pp. 209-210. 
de los ídolos responde a dicha táctica polémica de ataque y derribo de la cultura actual; lo que resulta especialmente llamativo en un capítulo como «Incursiones de un intempestivo», en el que Nietzsche carga contra Michelet, Carlyle, Liszt, Renan, Sainte-Beuve, Baudelaire... ${ }^{31}$ Esta estrategia de demolición responde a lo que podríamos denominar un 'pensamiento de resistencia' ante la constatación del proceso de 'decadencia del hombre'.

Ante la profundidad de la crítica, el pensamiento afirmativo de Nietzsche no parece ofrecer una reconstrucción discursiva. El carácter fragmentario de la escritura impide una exposición sistemática. Las propuestas nietzscheanas toman así como referencia una determinada vivencia (Erlebnis) que impide su reducción a un contenido conceptual. En El nacimiento de la tragedia la transformación de la cultura alemana está sujeta al redescubrimiento del fenómeno dionisíaco: el sentimiento musical como vivencia ofrece así la clave para la comprensión de la 'jovialidad' griega 32 . En el denominado período 'positivista' el programa de renovación de la cultura deja de estar vinculado a Alemania para adoptar una perspectiva cosmopolita. El 'espíritu libre', o más aún esa figura intermedia del 'buen europeo', abandona cualquier pretensión de proyecto nacionalista. En esta etapa cambia el punto de referencia: una concepción sui generis de la ciencia sustituye el anterior modelo del arte: de la reivindicación de la Grecia arcaica de la tragedia se pasa al elogio de la figura helenística del sabio. Sin embargo, los libros del periodo medio siguen manteniendo el tono de maximalismo utópico de la propuesta de resurrección del mito de $E l$ nacimiento de la tragedia. En el parágrafo 189 de El caminante y su sombra, que lleva el significativo título de «El árbol de la humanidad y la razón», Nietzsche concibe su tarea individual como la realización de pequeños ensayos que, a la larga, debieran producir un aumento general de la sabiduría. Se trataría por ello de un preparar la tierra para que, en su momento, el árbol pudiese cubrirla de flor y fruto 33 . Otro

31 KGW VI 3, p. 105 y ss.

32 Como ej. de este pensamiento analógico, en el que se parte de la experiencia artística como camino para la comprensión histórica — en este caso el de la música de Wagner como acceso a la cultura griega — puede leerse la anotación del invierno de 1872-1873, KGW III 4, 25[1], p. 166.

33 KGW IV 3, pp. 273-274. 
aforismo de La gaya ciencia, el 288, «Los elevados estados de ánimo», especifica en qué consistiría tal progreso de la sensibilidad humana: sería un experimentar de forma continua lo que ahora sólo sentimos en instantes excepcionales —esa disposición superior del alma que se mueve incesantemente entre la altura y la profundidad-, como si en realidad fuese éste su estado habitual ${ }^{34}$. El modelo de retraimiento del sabio del periodo medio se proyecta también hacia la transformación de la realidad; sólo que su radio de acción queda limitado al sentimiento o temperamento35. La última etapa presenta también una referencia semejante a un nivel de vivencia. El eterno retorno irrumpe primero como experiencia personal, como un sentimiento interno de transfiguración, a partir del cual toma forma la propuesta utópica de Nietzsche. Desde este momento todo su pensamiento gira en torno a esa mutación anímica (Stimmung, Erlebnis) que escapa a la exposición discursiva. Cuando en sus últimos escritos Nietzsche postula una política de segregación social, e incluso de aniquilación, como medida extrema ante la decadencia, el eterno retorno se erige en norma de su aplicación. Es referido entonces como «el gran pensamiento seleccionador» (der große züchtende Gedanke)36, encargado de llevar la humanidad hacia la gran decisión. Tal carácter de cría o selección (zǘchten) —el mismo término al que se aludía anteriormente al hablar del juego literario de adiestramiento y selección del lector (Zucht, Zü̈chtung)— radica en su capacidad destructiva, de manera que la humanidad habrá de escindirse entre los que sean capaces de aguantar el pensamiento del eterno retorno y los que perezcan por su causa ${ }^{37}$.

En definitiva, en los distintos periodos de la obra nietzscheana encontramos un proyecto utópico maximalista, basado en el rechazo del presente y en una propuesta para la transformación futura de la realidad, que toma como referencia un determinado tipo de vivencia. En esta situación de irreductibilidad conceptual, la escritura nietzscheana plantea un cuestionamiento de los límites de comunicación del len-

34 KGW V 2, pp. 288-289.

35 Sobre la cuestión del temperamento [das Temperament, véase KGW IV 2, pp. 49-51.

36 KGW VII 2, 25[227], p. 69.

37 Una curiosa enunciación de esta perspectiva de superación de la humanidad, en contraposición al jesuitismo y el socialismo, puede encontrarse en la anotación de primaveraverano de 1883, KGW VII 1, 7[238], p. 323. 
guaje. La táctica de 'adiestramiento' supone que sea el lector el que se acomode al texto. Los libros de Nietzsche, en especial los de su última etapa, trazan por tanto una búsqueda del lector: un descubrimiento de espíritus afines. Sus escritos constituyen de esta manera anzuelos - o redes 38 - que buscan atraer $\longrightarrow 0$ atrapar- a aquellos pocos para los que están destinados. Dado que el nivel de vivencia es incomunicable, la comunicación sólo será posible en el establecimiento de una comunidad con el lector, en la medida en que éste pueda reconocerse un miembro del 'nosotros' al que Nietzsche se dirige.

A continuación trataremos brevemente de seguir el itinerario por los distintos 'nosotros' que nos propone Nietzsche — desde los 'filólogos del porvenir' del periodo de El nacimiento de la tragedia hasta el 'nosotros, los hiperbóreos' de El Anticristo — así como su posterior disolución y sustitución por el 'yo' en Ecce homo. La obra concluye así con su propia autoanulación: el 'nosotros' se descubre como una ficción y el monólogo de la escritura deja paso al silencio.

Nietzsche albergó siempre el deseo — y la esperanza— de fundar una especie de comunidad espiritual: de hallar a los compañeros de viaje de su aventura solitaria. Antes de la publicación de El nacimiento de la tragedia, llega a proponer a Rohde abandonar la filología y fundar una Nueva Academia Griega, versión filosófica del proyecto de Bayreuth 39 . Catorce años después la misma esperanza se refleja en una carta a Köselitz. En esta ocasión la comunidad, erigida sobre los fundamentos de la gaya ciencia, se emplaza en la ciudad Niza para un futuro cercano ${ }^{40}$. Pero aparte de estos intentos frustrados, que no hacen sino poner de manifiesto la soledad y aislamiento en que vivía Nietzsche, lo cierto es que la noción ideal de comunidad va a encontrar su auténtico campo de despliegue en la escritura misma de la obra. El primer modelo de referencia de esta comunidad del 'noso-

38 Cf. KGW VII 3, 34[256], p. 227: «[...] todos mis escritos fueron hasta ahora redes arrojadas; deseaba con ello capturar hombres con almas profundas, ricas, joviales [...]» Para el paralelismo con Jesús en referencia a la imagen de las redes y el pescador de hombres, cf. Mateo, 4, 19 y 20.

39 Véase la carta a Rohde del 15 de diciembre de 1870, KGB II 1, pp. 165-168.

40 Véase la carta a Köselitz del 2 de septiembre de 1884, citada por Janz, op. cit., III, p. 265 . 
tros' se lo suministra a Nietzsche el proyecto wagneriano de Bayreuth. Su colaboración en el mismo consiste en desarrollar en la filología la tarea transformadora que Wagner, por aquellas fechas, estállevando a cabo en la música. Este empeño será la causa del equívoco que provocará el libro en los medios filológicos. A pesar de que es consciente de la incompatibilidad de $E l$ nacimiento de la tragedia con los estudios universitarios de filología, Nietzsche no desiste de la posibilidad de introducir su obra en los medios académicos. Tal es el sentido de la confesión que hace a su mentor Ritschl, por medio de una carta fechada en Basilea el 30 de enero de 1872, ante el silencio obstinado de éste tras la publicación del libro. En ella recalca que su auténtico propósito es servir de guía a las nuevas generaciones de filólogos, mostrándoles una nueva senda con la que acercarse a la Antigüedad 41 . El rechazo de sus colegas y la posterior polémica con un jovencísimo Wilamowitz le demuestran la inviabilidad de sus planes de reforma de la filología. Es dentro de esta actitud crítica que Nietzsche va a adoptar una primera formulación del 'nosotros'. Se trata de la denominación 'filólogos del porvenir' con la que Nietzsche agrupa a sus futuros camaradas en la tarea de renovación de los estudios clásicos. A pesar de la crítica de Wilamowitz, Nietzsche se mantendrá fiel a la designación, e incluso, años después, puede aún hallarse un eco de la misma en la proclama de los 'filósofos del porvenir' de Más allá del bien y del malt2. Un texto interesante de este primer periodo, en el que ya se intuye la táctica literaria del 'nosotros', es el segundo de los Cinco prólogos a cinco libros no escritos, «Pensamientos sobre el porvenir de nuestros establecimientos de enseñanza». Este prefacio constituye una exhortación al lector para unirse al campo de batalla de la cultura. El escrito comienza con un rechazo de la actualidad. Ante la precipitación del presente, el lector que busca Nietzsche pertenece, por definición, a una época distinta. Esto supone que el libro está destinado a muy pocas personas, precisamente a aquellas capaces de una medi-

41 KGB II 1, p. 282.

42 J. I. Porter, en su reciente libro Nietzsche and the Philology of the Future (Stanford University Press, 2000, p. 15), sitúa por primera vez la mención del término 'filólogo del futuro' en una carta dirigida a Paul Deussen, fechada el 2 de junio de 1868. El término reaparecerá posteriormente en la polémica con Wilamowitz, quien dió a su panfleto contra El nacimiento de la tragedia el título Zukunftphilologie. 
tación seria sobre el futuro. Para ello, el lector habrá de acompañar al autor por un arduo camino; quizás al principio de manera indecisa - guiado únicamente por el instinto- sin conocer aún cuál puede ser el final, pero con la certeza de estar preparando la senda para una generación futura. Los que se decidan a seguirle habrán de tomar de esta manera conciencia del estado actual de 'barbarie' inherente a nuestra formación. Al final del prólogo Nietzsche hace una llamada a esos lectores ideales, convocados a participar, desde la altura originaria del espíritu alemán, en la decisiva batalla de la cultura. El libro está destinado a convertirse en su heraldo, aunque, posteriormente, en el fragor de la lucha, ya nadie habrá de volver hacia él la mirada 43 .

En este breve texto hallamos algunos de los rasgos característicos de la posterior construcción del 'nosotros', tales como: una exhortación al lector que lo contrapone a su propia época, la adopción de una tarea de transformación del futuro o la representación de una 'comunidad' intelectual, cuya labor sólo podrá ser aprovechada por próximas generaciones. Pero, a pesar de estas prenociones del 'nosotros' - referencia al proyecto de Bayreuth, utilización de la fórmula 'filólogos del porvenir', proclama de la batalla de la cultura-, la obra de Nietzsche en esta primera etapa no desarrolla el filtro de 'selección' del lector que será característico de libros posteriores. El nacimiento de la tragedia y la serie de las Intempestivas están concebidos en la forma usual de ensayo. El autor expone de manera lineal a un público no especialista, con ausencia de referencias bibliográficas y notas a pie de página - hecho este especialmente llamativo en una obra de contenido 'filológico' como El nacimiento de la tragedia_- No existe en estos libros una figura que, retóricamente, dirija el discurso hacia un determinado tipo de lector. Ella sólo hará su aparición con el cambio temático y de estilo de Humano, demasiado bumano. La búsqueda de una voz propia, independiente de los modelos de juventud de Schopenhauer y Wagner, conlleva la adopción de la forma aforística y, al mismo tiempo, el descubrimiento del 'nosotros' en la fórmula del 'espíritu libre'.

43 KGW III 2, p. 257. Sobre esta llamada a la batalla de la cultura en nombre de una generación futura, cf. la carta a Gersdorff del 4 de febrero de 1872, KGB II 1, p. 286. 
Con Humano, demasiado bumanose produce aparentemente una inversión de la perspectiva del pensamiento de Nietzsche. El modelo de la ciencia sustituye al arte como principio rector de la cultura. Se trata en este libro, sin embargo, de un concepto muy particular de ciencia, entendida básicamente como una forma de vivencia. De ahí que Nietzsche pueda definir su 'método científico' como un tipo de 'experimentación' (experimentieren, versuchen), en la que lo esencial es recorrer, hasta sus límites últimos, todo el campo de lo vivido. Nietzsche expresa esta idea por medio de la asociación de los términos Versuchy Versuchung, respectivamente 'ensayo' y 'tentación' 44 . La figura del 'espíritu libre', que hace su aparición en Humano, demasiado bumano, lleva a cabo esta experimentación de lo vivido en la forma de control de laciencia —una especie de quietud contemplativadel sabio-que vaasercaracterística del periodo mediodelaobrade Nietzsche. Al mismo tiempo, el 'espíritu libre' sustituye en esta etapa al genio artista en la tareade transformación de lacultura. El librose propone así descubrir, entre sus posibles lectores, a tales aliados desconocidos. El último aforismo, con la aparición de la figura del 'caminante', constituye una exhortación a ese nosotros que, desde una transformación de la sensibilidad — desde la ausencia de una última meta y la reflexión en soledad—, llevaráa cabo la propuesta utópica de la filosofía de la mañand ${ }^{5}$.

La búsqueda del 'nosotros' constituye desde este momento uno de los principales argumentos —retóricos- de la obra. Los libros publicados establecen de ahora en adelante un filtro de 'selección', instaurándose así una comunidad en la escritura. El poder de atracción de la prosa nietzscheana culmina la identificación del lector con ese 'nosotros' que se separa de la tradición y la cultura. Las fórmulas se multiplican: 'Nosotros': los inmoralistas, los impávidos ${ }^{46}$, los filóso-

44 Un ejemplo paradigmático de esta concepción del 'método científico' como 'experimentación' o 'ensayo' lo podemos encontrar en el parágrafo 432 de Aurora, aforismo que lleva el sugerente título de «Investigador y tentador» (Forscher und Versucher), KGW V 1, p. 270. Respecto al juego de palabras Versuch-Versuchung, cf. la descripción de los 'filósofos del porvenir' del $\$ 42$ de Más allá del bien y del mal, KGW VI 2, p. 55: «[...] podrían estos filósofos del futuro ser designados, con justicia, o quizá también injustamente, como tentadores $[$ Versucher $]$. Este nombre es por último él mismo sólo una tentativa $[$ Versuch $]$ y, si se quiere, una tentación [Versuchung]».

45 KGW IV 2, pp. 374-375.

$46 \mathrm{O}$ 'los que no tenemos miedo’: «Wir Fürchtlosen» es el título del quinto libro de La gaya ciencia, añadido en 1886. 
fos del porvenir, los hiperbóreos... La táctica polémica de los últimos libros acentúa el efecto de escisión. Durante la lectura resulta difícil sustraerse a la subyugación del texto y no tomar parte en la querella que plantea. En esta estrategia de derribo, el 'nosotros' se afirma en el poder - y placer- de la negación: autor y lector se identifican en el reconocimiento e incriminación de lo 'decadente'... Más allá del bien y del malcontiene ya los recursos retóricos de los que se va a servir Nietzsche en su lucha final contra la decadencia. Consistirán básicamente en una maximalización del tono crítico, seguido por la previsión del pronto advenimiento de un pensamiento liberador: ya sea en la forma del eterno retorno, del amor fati, del gran mediodía... Dentro de esta táctica encontramos en Más allá del bien y del mal una reformulación de la figura del espíritu libre como etapa intermedia que prepara el camino a los 'filósofos del porvenir'. Estos últimos habrán de retomar, cuando llegue su momento, la senda de los filósofos-reyes de Platón. Se otorgarán entonces a sí mismos la facultad de legislar, al convertir su 'voluntad de verdad' en 'voluntad de poder' 47 . Serán por ello capaces de ofrecer una nueva valoración que se oponga al avance de la decadencia de la sociedad democrática ${ }^{48}$. A pesar de los cambios de formulación, esta concepción del 'nosotros' mantiene el mismo esquema que las anteriores: la transformación de la realidad pasa por un cambio de la sensibilidad —en este caso el eterno retorno-que de momento sólo podemos preparar para un futuro: el de 'los filósofos del porvenir', 'los señores de la tierra' o 'el superhombre'.

Sin embargo, en el mismo momento en que Nietzsche idea el proyecto utópico de los filósofos del futuro, la noción del 'nosotros' comienza a resquebrajarse. Una anotación póstuma de junio-julio 1885 nos muestra la hondura de esta crisis. En ella Nietzsche reconoce no haber encontrado a nadie que piense como él, que quiera «lo que quiere mi voluntad más oculta». Los nuevos filósofos - los expositores «de la auténtica jerarquía y de la diferencia de valor entre los hombres»—-están destinados a ser ermitaños y sufrir la soledad. Escondi-

47 Cf. KGW VI 2, pp.148-149. El 'filósofo del porvenir' será el único capaz de legislar, ya que también será el único capaz de crear nuevos valores. La transformación de la 'voluntad de verdad' en 'voluntad de poder' viene en consecuencia determinada por la conversión del conocer (Erkennen) en crear (Schaffen).

48 Cf. KGW VI 2, pp. 128-130. 
dos tras sus máscaras, no reconocerán a sus semejantes y, aun en el caso de que dos llegaran a encontrarse, se defraudarían mutuamente ${ }^{49}$. En el prólogo de 1886 a Humano, demasiado bumano la crisis se acentúa. El 'espíritu libre' se descubre ahora como una ficción solitaria æ «como espectros y juegos de sombra de un ermitaño». En realidad, dice Nietzsche, no ha habido nunca tales 'espíritus libres': ellos han sido únicamente una manera de superar la enfermedad, el aislamiento, la acidia, la inactividad ${ }^{50}$. Esta situación va a culminar con una autosupresión del 'nosotros' y su sustitución por el 'yo' en El Anticristo y Ecce homo. A partir de ese momento, la obra puede abandonar su pretensión utópica - su aspiración de transformación del futuro-y convertirse en 'programa político' de oposición a la decadencia ${ }^{51}$.

El proceso queda perfectamente reflejado en El Anticristo. El prólogo presenta la habitual 'selección' del lector. En él Nietzsche confiesa que el libro pertenece, al menos por el momento, a una muy reducida minoría - tal vez sólo a aquellos que hayan comprendido el Zarathustra-; por lo demás su significado real se proyecta hacia el futuro: «Sólo me pertenece el pasado mañana. Algunos han nacido póstumamente [...]»52 El primer aforismo introduce una nueva versión del 'nosotros', los hiperbóreos, en referencia a Píndaro: «Mirémonos a la cara. Somos hiperbóreos, — sabemos muy bien cuán aparte vivimos. 'Ni por tierra ni por mar hallarás el camino hasta los hiperbóreos': esto ya lo sabía Píndaro de nosotros. Más allá del norte, del hielo, de la muerte — nuestra vida, nuestra felicidad...»53 Pero cuando Nietzsche llega a la conclusión del libro el 'nosotros' desaparece para dejar paso al 'yo', a ese 'yo' omnipresente que, en Ecce homo, va a convertirse en el único referente del discurso: «Con ello llego a la conclusión y dicto mi sentencia. Yo condeno el cristianismo, alzo con-

49 KGW VII 3, 36[17], pp. 281-283.

$50 \mathrm{KGW}$ IV 2, p. 9.

51 Tal sería el origen del 'partido de la vida' anunciado en fragmentos póstumos como KGW VIII 2, 11[236], p. 335 y proclamado, como aniquilación de todo lo parasitario y degenerado, en Ecce homo, KGW VI 3, p. 311.

$52 \mathrm{KGW}$ VI 3, p. 165. Resulta interesante comparar este pasaje con la anotación de verano-otoño 1884, KGW VII 2, 26[246], p. 213: «En este siglo de las impresiones rápidas y superficiales el libro más peligroso no resulta peligroso: busca los cinco, seis espíritus que sean lo suficientemente profundos. Por lo demás — qué importa si ayuda a destruir estaépoca».

53 KGW VI 3, p. 167. 
tra la Iglesia cristiana la más terrible de todas las acusaciones que jamás un acusador haya proferido de sus labios. [... $] \gg 54$

Este momento puntual de El Anticristo marca, a nuestro parecer, una especie de autodisolución de la ficción retórica en la que se sustentaba la obra. El 'nosotros' ha desaparecido: ya no hay razón para buscar a nuestros semejantes, a aquellos que lucharán a nuestro lado en la batalla futura de la cultura, a los compañeros de viaje en busca de la filosofía de la mañana, a los filósofos-legisladores del porvenir... La búsqueda de Zaratustra del 'hombre superior' concluye en un fracaso. Pero a Zaratustra aún le queda el superhombre. Al final del libro el león riente junto a la bandada de palomas anuncian la hora del 'gran mediodía'55. Ahora en cambio, a partir de la proclama de El Anticristo, ya no es necesaria ninguna referencia al futuro. El 'proyecto utópico' se transforma en 'programa político'; por un lado, porque se busca una realización inmediata, no diferida; por el otro, porque para tomar las 'grandes decisiones' casi más necesario que saber quiénes somos, es saber quién es nuestro enemigo. Una vez determinado el agente de la decadencia, puede procederse a su inmediata aniquilación. Este paso supone en realidad, más allá del hundimiento físico, la disolución de la obra. El programa político del partido de la vida resulta incompatible con el proyecto utópico del amor fati. ¿Cómo es posible proclamar la 'inocencia del devenir' y postular al mismo tiempo el exterminio de todo lo degenerado, fracasado, enfermo?...

El derrumbe del 'nosotros' marca el punto final de esta identidad de la vida y la escritura. Sin embargo, aún queremos - a modo de conclusión-hacer referencia a otro aspecto determinante en la 'pasión literaria' de Nietzsche: la doble experiencia de la salud y la enfermedad. El ideal de salud acabará convirtiéndose, por efecto del juego de transparencia de la escritura nietzscheana, en la meta del proyecto utópico: el anhelo de cambiar de vida —ese deseo que se insinúa aun en los peores momentos de la enfermedad-se trasluce en la palabra escrita y deviene, finalmente, aspiración colectiva.

54 Ibid.

55 KGW VI 1, p. 404. 


\section{EL IDEAL DE SALUD}

Ha sido Pierre Klossowski quien, con su descripción de los 'estados valetudinarios de la cultura', ha puesto un mayor énfasis en la relevancia de la experiencia de la enfermedad y la salud en la génesis del pensamiento y la obra de Nietzsche ${ }^{56}$. La evolución de la escritura nietzscheana seguiría, según Klossowski, un movimiento de vaivén entre euforia y depresión, una lógica de almacenamiento y gasto de energía, de acuerdo con la sucesión de estados de empeoramiento de la enfermedad y recuperación de la salud. La interpretación de Klossowski pone en un primer plano un hecho que, a pesar de las diversas confesiones de Nietzsche a este respecto, suele pasar desapercibido en muchas de las lecturas globales de su filosofía. La importancia fundamental de la salud, como meta o instancia de la transvaloración, supone una asimilación de la enfermedad: el ideal de salud sólo adquiere pleno sentido para un persona enferma - para una persona sana la salud no es ningún objetivo. La discusión sobre las causas de la dolencia mental de Nietzsche, y si ella ejerció alguna influencia en la elaboración de su pensamiento, pierde todo sentido una vez se entra en la lógica salud-enfermedad que gobierna la obra. La enfermedad estuvo desde un primer momento en el centro de la reflexión de Nietzsche: su filosofía tiende precisamente, por utilizar los términos característicos del periodo de madurez, a 'incorporarla' (eimverleiben), a llevar la experiencia hasta sus últimas consecuencias con vistas a su 'superación' (Überwindung).

El mismo Nietzsche en Ecce homo —en la segunda sección de «Por qué soy tan sabio»- reconoce la importancia fundamental de la sucesión salud-enfermedad en el origen de su pensamiento. Se trata de la doble cara de su existencia, la que le permite hundirse en el instinto de la decadencia y ascender hacia la sobreabundancia de la vida. Este tránsito, perfeccionado tras un largo ejercicio, es el que permite realmente invertir las perspectivas: sólo a partir de él se hace posible una 'transvaloración de los valores'. Nietzsche cierra el párrafo confesando que ha hecho de su voluntad de salud, de vida su filosofía...57 El ideal

56 Cf. el inicio de P. Klossowski, Nietzsche et le cercle vicieux.

57 KGW VI 3, pp. 264-265. 
de salud tiene así en primer lugar un sentido personal. La mala elección de un lugar de residencia, de unos determinados hábitos alimenticios provoca la enfermedad. Encontrar el clima y la dieta adecuados constituye la primera condición que ha de cumplirse para recuperar la salud. Las confesiones de Nietzsche sobre sus preferencias culinarias o sobre los efectos del clima en su organismo en el capítulo «Por qué soy tan listo» de Ecce homo no suponen ninguna novedad con respecto a la correspondencia o cuadernos de notas ${ }^{58}$. La enfermedad se manifiesta como resultado de un error inicial: se escoge una forma de vida equivocada y la 'razón' del cuerpo protesta. En el caso de Nietzsche, la elección consistió en su carrera de erudito y profesor universitario. La dolencia que le obligó a abandonar la cátedra de literatura y lengua griegas tiene por ello un sentido ambiguo. Es, por decirlo a la manera de Ecce homo, tanto un signo de decadencia como una marca de plenitud; pues si Nietzsche pudo precisamente abandonar aquella vida, fue gracias a la enfermedad. Sólo ella le condujo a la razón59. En este punto puede observarse el desplazamiento del ideal de salud desde su sentido personal al de la escritura de la obra. Si la actividad académica es el origen de la enfermedad, cada paso que le aleja de la Universidad, y le concede la libertad de escribir, es un avance en la recuperación de la salud ${ }^{60}$. El momento de vitalidad más bajo se sitúa en Humano, demasiado bumano y El caminante y su sombra. En estos libros Nietzsche trata meramente de sobrevivir, pero con ello está en realidad poniendo las bases para la posterior explosión — la descarga de exuberancia vital - de La gaya ciencia. Cada libro es así un peldaño hacia una transformación definitiva. La escritura se convierte de esta manera en instrumento para la recuperación de la salud. El descubrimiento de la tarea, la realización de la obra impuesta por el pensamiento del eterno retorno, representa el cambio decisivo de vida: $\mathrm{y}$ al mismo tiempo la culminación de la labor de la enfermedad. La metá-

58 Para la discusión sobre el clima y la alimentación en Ecce homo, véase KGW VI 3 , pp. 279-281. Sobre esta cuestión en la correspondencia, cf. las cartas a Rohde, del 24 de mayo de 1881 (KGB III 1, pp. 76-79) a Köselitz del 21 de enero de 1887 (KGB III 5, pp. 11-13), etc.

59 KGW VI 3, p. 281.

60 Aparte de Ecce homo, cf. sobre esta cuestión la carta a Overbeck del 15 de julio de 1886, KGB III 3, p. 205. 
fora de la sanación se desplaza por último al 'proyecto utópico' y a su disolución en 'programa político'. En el primer caso, la salud se presenta como rasgo definitorio del 'nosotros'. Se trata de aquella 'gran salud' anunciada al final libro quinto de La gaya ciencia, un estado superior de afirmación que nos permite —a 'nosotros' los nuevos filósofos, los 'argonautas del ideal'- recorrer toda la gama de estados del alma; y ser así conquistadores, exploradores, artistas, legisladores, santos, sabios, científicos, adivinos, anacoretas...61 Es también por ello una salud que no puede privarse de nada y mucho menos de la enfermedad, en la que encuentra su origen 62 . Pero cuando el 'proyecto utópico' del nosotros pasa a ser un 'programa político' del yo, el ideal de salud sirve también de base a la política de aniquilación del partido de la vida: ante la enfermedad de la sociedad sólo cabe la amputación del miembro enfermo ${ }^{63}$.

El ideal de salud cierra de esta manera el círculo de la escritura de Nietzsche. La palabra escrita hace coincidir las aspiraciones personales y el destino de la humanidad. Cuando la búsqueda del 'nosotros' se derrumba y sólo queda el aislamiento del 'yo', los elementos literarios de comunicación se vuelven superfluos: la obra encuentra su propia disolución en la parodia de Ecce homo. Pero también este final forma parte de la grandeza del escritor Nietzsche. El hecho de que reproduzca toda su trayectoria vital hasta el hundimiento en el silencio y la locura en la palabra escrita, el deseo de un cambio radical gracias a un libro - como la nueva era que habría de surgir tras El Anticristo-, la obsesión de escribir y publicar — que permitía a un Nietzsche ya totalmente enajenado corregir las pruebas de imprenta de Los ditirambos a Dioniso-... todo esto pertenece al destino y la tragedia personal de Nietzsche, pero también pertenece a su destino y tragedia literaria, y con ello al destino y tragedia de nuestra propia cultura.

61 KGW V 2, pp. 317-318.

62 Para esta salud que no puede, ni quiere privarse de la enfermedad, cf. por ej. la anotación de agosto-septiembre de 1885, KGW VII 3,

63 Para la amputación del miembro enfermo en el programa de aniquilación del partido de la vida, cf. KGW VIII 3, 15[13], pp. 